\title{
Sauropod trackways of the Iberian Peninsula: palaeoetological and palaeoenvironmental implications
}

\author{
D. Castanera ${ }^{1 *}$, B.Vila ${ }^{1,2}$, N.L. Razzolini², V.F. Santos ${ }^{3,4}$, C. Pascual ${ }^{5}$, J.I. Canudo ${ }^{1}$ \\ ${ }^{1}$ Grupo Aragosaurus-IUCA. Paleontología. Facultad de Ciencias. Universidad de Zaragoza. \\ c/ Pedro Cerbuna, 12, 50009 Zaragoza, Spain \\ ${ }_{2}^{2}$ Institut Català de Paleontologia Miquel Crusafont. Carrer Escola Industrial, 23, E-08201 Sabadell (Barcelona), Spain \\ ${ }^{3}$ Museu Nacional de História Natural e da Ciência da Universidade de Lisboa, Rua da Escola Politécnica, 58, \\ 1250-102 Lisboa, Portugal \\ ${ }^{4}$ Centro de Geofísica da Universidade de Coimbra (FCT-MCTES), Av. Dr. Dias da Silva, 3000-134 Coimbra, Portugal \\ ${ }^{5} \mathrm{c} /$ Real, 65. 42002 Soria, Spain
}

e-mail addresses: dcastanera@unizar.es(D.C., *correspondingauthor); bernat.vila@unizar.es (B.V.);novella.razzolini@icp.cat (N.L.R.); vsantos@museus.ul.pt (V.F.S.); capascual-1@telefonica.net (C.P.); jicanudo@unizar.es (J.I.C.)

Received: 14 September 2012 / Accepted: 4 December 2013 / Available online: 25 February 2014

\begin{abstract}
More than a hundred sauropod tracksites, ranging in age from Middle Jurassic (Bathonian) to Late Cretaceous (Maastrichtian), are reported from the Iberian Peninsula (Spain and Portugal). Sauropod trackway orientation patterns throughout an entire geographic area such as the Iberian Peninsula and over different time periods may provide new data about the palaeoecology and behavioural patterns of sauropods. The studied tracksites exhibit two main trackway orientation patterns, directional and random, indicating different behaviours in gregarious or solitary (milling) individuals. Gregarious behavioural patterns are mainly observed within Parabrontopodus/Breviparopus-like and Brontopodus-like ichnotypes of a single size class (either small or medium-sized), indicating age segregation. Among the gregarious sauropods the former ichnotype is linked with inland environments, while the latter is mainly linked with coastal environments. Solitary trackways are mainly of medium-sized to large individuals, are also linked with both inland (Parabrontopodus/Breviparopus-like) and coastal environments (Parabrontopodus/Breviparopus-like, Brontopodus-like), and belong to the above-mentioned ichnotypes as well as to Polyonyx-like ichnotypes. Thus, no obvious link between gregarious behaviour and the palaeoenvironmental setting can be inferred from the sauropod track record of the Iberian Peninsula. Nonetheless, sauropod trackways showing titanosauriform characters (Brontopoduslike) are more common in coastal environments, contrary to what might be expected given this group's apparent taxonomic preference for inland environments.
\end{abstract}

Keywords: Sauropod trackways, palaeoecology, gregarious behaviour, Jurassic, Cretaceous, Iberian Peninsula

Resumen

El registro Ibérico (España y Portugal) de icnitas de saurópodos está representado por más de cien yacimientos cuya edad varía desde el Jurásico Medio (Batoniense) al Cretácico Superior (Maastrichtiense). El estudio de la orientación de los rastros, en un área determinada como la Península Ibérica y en diferentes edades, nos ha permitido obtener nuevos datos sobre el comportamiento de los saurópodos. Los rastros de los yacimientos estudiados presentan dos patrones de movimiento distintos, direccionales y aleatorios, que reflejan distintos comportamientos en individuos gregarios o solitarios (deambulantes). El patrón que indica comportamiento gregario se observa en los icnotipos "Parabrontopodus/Breviparopus-like" y "Brontopodus-like" en saurópodos del mismo tamaño (pequeño o medio), lo que indica segregación por edad. El primer icnotipo se ha conservado en sedimentos depositados en ambientes terrestres mientras que el segundo lo hace fundamentalmente en ambientes costeros. Los rastros solitarios son, en su mayoría, de saurópodos de tamaño medio o grande, conservados tanto en medios terrestres ("Parabrontopodus/Breviparopus-like"), como costeros ("Parabrontopodus/Breviparopus-like" y "Brontopodus-like") y pertenecen a los dos icnotipos mencionados anteriormente y a un tercero: "Polyonyx-like". Por lo tanto, no hay una significativa influencia paleoambiental en el registro del comportamiento gregario de los saurópodos ibéricos. Sin embargo, los rastros saurópodos que muestran caracteres Titanosauriformes (Brontopodus-like) son más frecuentes en los medios costeros de la Península Ibérica. Estos resultados son diferentes a los expuestos por otros autores que apuntan una aparente preferencia de los Titanosauriformes por los medios terrestres. 


\section{Introduction}

Palaeoichnology is an important complement to the study of the skeletal fossil record, especially in drawing palaeobiological and palaeoecological inferences (see Thulborn, 1990; Lockley, 1991). In Europe, gregarious behaviour in dinosaurs has been inferred on the basis of ichnological evidence for different dinosaur groups; these include theropods, ornithopods and sauropods (e.g., Lockley et al., 1994a; PérezLorente et al., 1997; Lockley and Meyer, 2000; Day et al., 2004; Barco et al., 2006; Mezga et al., 2007; García-Ortíz de Landaluce and Díaz-Martínez, 2008; Marty, 2008; Castanera et al., 2011). On a worldwide scale, parallel sauropod trackways with regular intertrackway spacing have been interpreted as a "herd", "gregarious behaviour", "gregariousness", or simply "social behaviour" (Ostrom, 1972; Lockley et al., 1986; Lockley, 1991; Lockley et al., 2002a; 2002b; Myers and Fiorillo, 2009), implying that the individuals were moving together simultaneously.

On the Iberian Peninsula a great number of sauropod tracksites, are known today, ranging in age from Middle Jurassic to Late Cretaceous (see Pérez-Lorente, 2003; Royo-Torres, 2009 , for syntheses) and preserved in different palaeoenvironmental settings such as shallow marine, transitional and lacustrine environments (Santos, 2003; Vila et al., 2008; Moratalla, 2009; Moratalla and Hernán, 2010; Cobos, 2011). Nonetheless, gregarious behaviour of sauropods has only been described at two tracksites: the Pedra da Mua level 3 tracksite in Portugal (Lockley et al., 1994a) and Las Cerradicas tracksite in Spain (Castanera et al., 2011). The aims of this paper are to provide an overview of the sauropod trackway record of the Iberian Peninsula, to describe in greater detail the tracksites of Las Cuestas I, Miraflores I and Fumanya Sud (Fig.1), and to analyse the trackway orientation patterns of the most important sites. Afterwards, possible links between behavioural patterns (parallel trackways revealing gregarious behaviour or random trackway disposition - milling) and ichnotaxonomy and the palaeoenvironment are discussed.

\section{Geographical and geological setting of the Iberian sauropod tracksites}

The Iberian sauropod tracksites are located in four broad areas (Fig. 1): the Lusitanian Basin (Santarém and Setúbal districts, Central Portugal) in Portugal, the Cantabrian Range (province of Asturias), the Iberian Range (provinces of Burgos, La Rioja, Soria, Teruel and Valencia) and the Pyrenees (province of Barcelona) in Spain.

\subsection{Lusitanian Basin (Portugal)}

The main Portuguese sauropod tracksites are found in shallow marine limestones in different stratigraphic units. The Galinha tracksite is included within the lower part of the sequence of the Serra de Aire Formation (Lower Bathonian), which was deposited in lacustrine, paralic and very shallow, restricted marine conditions (Santos et al., 1994; Azeredo, 2007; Santos et al., 2009). The Avelino tracksite (Kimmeridgian) belongs to the Azoia Unit, which was deposited in transitional environments (Lockley and Santos, 1993; Santos, 2003). The Pedra da Mua track-bearing levels (Tithonian) belong to the Espichel Formation, which was deposited in shallow marine conditions (Lockley et al., 1994a; Santos, 2003).

\subsection{Cantabrian Range (Asturias)}

Here the sauropod tracksites are located along the Asturian coast, where the Upper Jurassic materials outcrop in the cliffs and some rather small tracksites are located (García-Ramos
Fig. 1.- Simplified geographical and geological setting of the main sauropod tracksites from the Iberian Peninsula (for more information see references in the text).

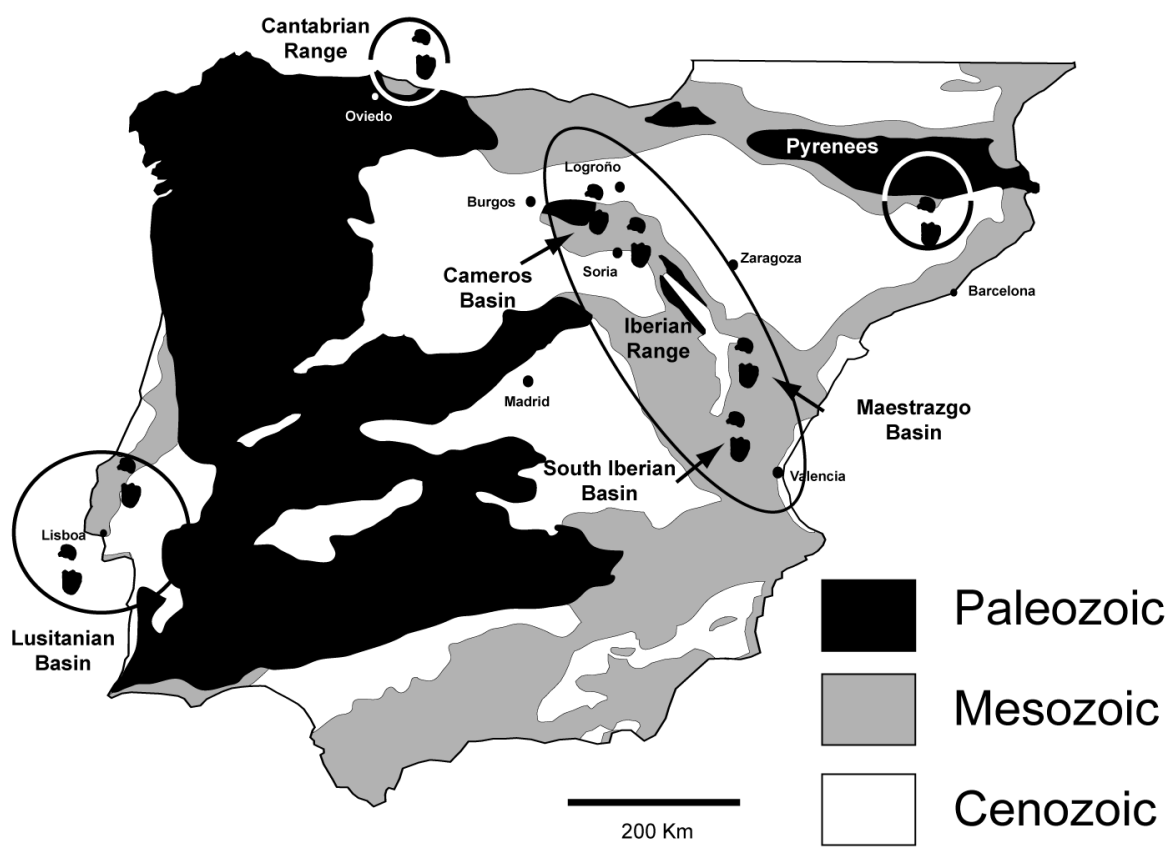


et al., 2006; Lockley et al., 2008). Indeed, the exposed surfaces are not large enough to be able clearly to identify sauropod trackways and hence orientation patterns.

\subsection{Iberian Range (Burgos, La Rioja, Soria, Teruel, Valencia)}

The Iberian Range contains the great majority of the tracksites, which range in age from the Tithonian (Late Jurassic) to the Aptian (late Early Cretaceous).

The Maestrazgo Basin (province of Teruel) and the South Iberian Basin (provinces of Valencia and Teruel) in the central and southern part of the Iberian Range contain the oldest tracksites. These belong principally to the Villar del Arzobispo Formation, which is Tithonian-Berriasian in age and is made up of carbonates and terrigenous materials associated with a wave-dominated delta, representing a transitional environment between a shallow marine carbonate platform and a terrestrial environment (see Cobos, 2011 and references therein). The Cameros Basin, in the northern part of the Iberian Range (provinces of Burgos, La Rioja and Soria), has the greatest number of sauropod tracksites. The main tracksites are principally preserved in lacustrine environments from two concrete stratigraphic units: the Huérteles Formation (Oncala Group) and the Enciso Group, which outcrop in the Eastern Cameros sub-basin in the provinces of Soria and La Rioja, respectively (see Moratalla, 2009; Moratalla and Hernán, 2010, and references therein). The former is Berriasian in age and represents "an extensive, tectonically controlled complex record of alluvial plain systems distally connected with playalake systems, with an asymmetric arrangement of different sedimentary belts" (see Moratalla and Hernán, 2010 and references therein, but see also Quijada et al., 2010). The sauropod tracksites, as well as the other dinosaur tracksites, are located in the proximal facies of the basin. On the other hand, the latter is Aptian in age and was deposited in a lacustrinepalustrine system (Moratalla and Hernán, 2010).

\subsection{Pyrenees (Barcelona)}

In the southeastern Pyrenees, north of the province of Barcelona, various sauropod tracksites have been reported, as the most notably the Fumanya tracksites. These vast quarry localities contain more than 50 trackways (Schulp and Brokx, 1999; Vila et al., 2005, 2008), abundantly preserved in thin marly beds, within a lagoonal (mudflat) setting with many brackish invertebrates, vertebrates, and plant remains (Villalba-Breva et al., 2012). The track-bearing levels are within the lower Tremp Formation, in the so-called "Grey Unit", and are Early Maastrichtian in age (Oms et al., 2007).

\section{Material and methods}

Of more than one hundred tracksites in the Iberian Peninsula (Pérez-Lorente, 2003; Santos, 2003; Hernández Me- drano et al., 2008; Royo-Torres, 2009; Cobos, 2011), about 60 sites exhibit distinguishable trackways, while the others are mainly "dinoturbated" surfaces without any clear trackways preserved. At some of the former sites, one or several trackway-bearing levels are large enough to allow inferences about gregariousness, and these tracksites (or levels) are the focus of this study. The sauropod tracksites were selected (Supplementary online material), taking into account the surface of the tracksites, on the basis of the following features: parallel trackways belonging to the same morphotype, with a similar mode of preservation, and displaying close and regular intertrackway spacing and similar speed values. The total transect length of the trackways or the width of the group (the distance between the leftmost trackway and the rightmost trackway) and the pace rhythm (similar pace cadence during locomotion) are also analysed.

In the case of two or more trackways, the orientation patterns with parallel trackways belonging to the same ichnotaxon, with a similar mode of preservation (in order to reduce or exclude time-averaging), displaying a close and regular intertrackway spacing and a similar locomotion speed are considered to be evidence of gregarious behaviour. However, due to insufficient tracksite size ("transect length"), there is often uncertainty as to whether or not parallel trackways represent an entire group (herd) or form part of a larger group.

Tracksites with a moderate to high dinoturbation index (Lockley, 1991) were excluded from the analysis because of difficulties in distinguishing individual trackways; these are considered to be evidence of "group activity" (sensu Ostrom, 1972). The data (Supplementary online material) are based on our measurements at some of the studied tracksites and/or were collected from the literature. The trackway direction for each trackway was calculated and plotted in rose diagrams using the software ROSE 2.1.0. For trackways showing changes in direction we measured various directions representing the average in the plots. The orientation unit in the rose diagrams is $5^{\circ}$ and the circular lines (when present) correspond to one unit (1 trackway).

The areas of the tracksites were estimated directly from maps. Size classes have been differentiated according to the proposal of Marty (2008). Thus, according to the pes length (PL) the sauropod can be considered tiny ( $\mathrm{PL}<25 \mathrm{~cm}$ ), small $(25 \leq \mathrm{PL} \leq 50)$, medium-sized $(50 \leq \mathrm{PL} \leq 75)$ and large $(\mathrm{PL} \geq 75)$. The locomotion speed was established from the original papers, except in the case of the Fumanya Sud tracksite where it was calculated according to the formula proposed by Alexander (1976): $\mathrm{v}=0.25 \mathrm{~g}^{0.5 *} \mathrm{SL}^{1.67 *} \mathrm{~h}^{-1.17}(\mathrm{~g}=$ constant of gravity; $\mathrm{SL}=$ stride length; $\mathrm{h}=$ hip height $=4.586 * \mathrm{PL}$ according to González-Riga, 2011). The trackways have been named with acronyms, that refer to the name of the tracksite and a number that represents the number of the trackway within the tracksite (e.g. LCU-I-17 = trackway 17 from Las Cuestas I tracksite). This nomenclature follows the original paper for each tracksite. The classification of the sauropod trackways 


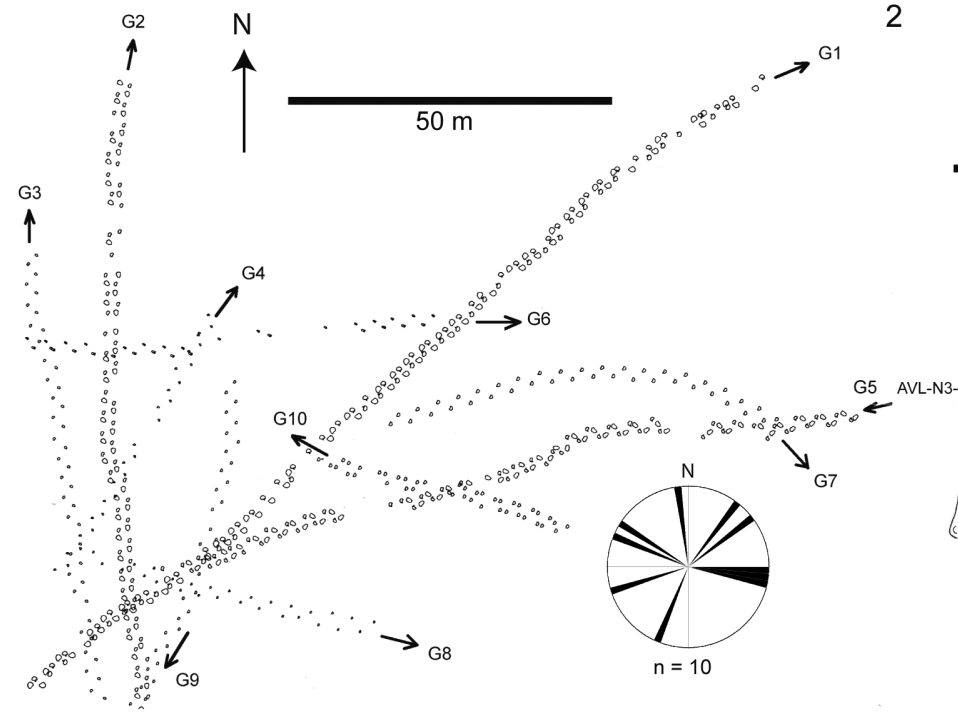

3

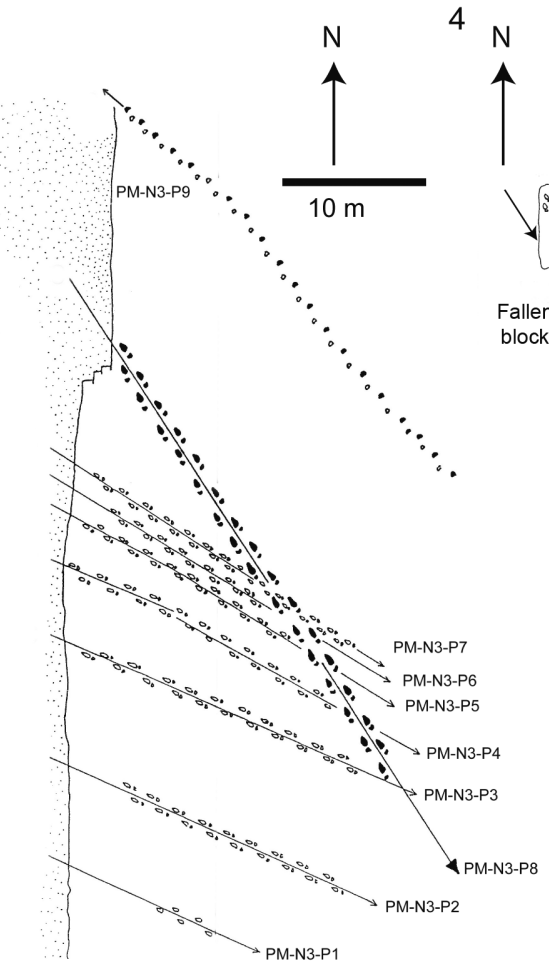

$\mathrm{N}$

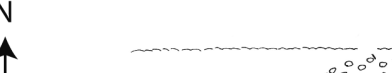

$10 \mathrm{~m}$
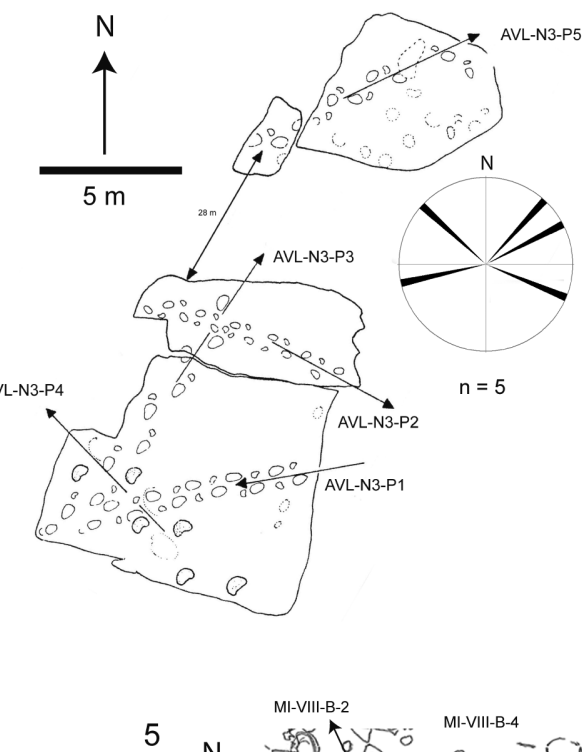

5
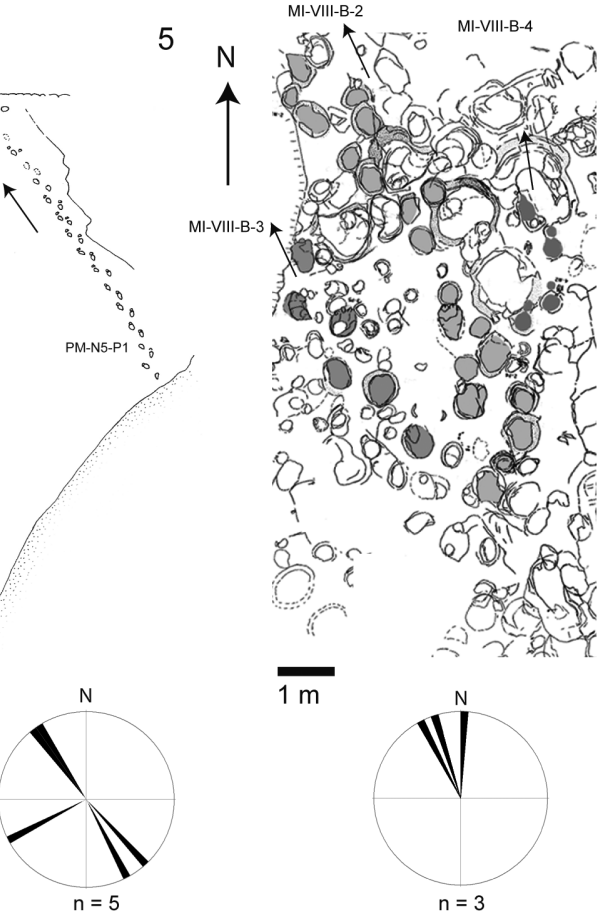

$\overline{1 \mathrm{~m}}$

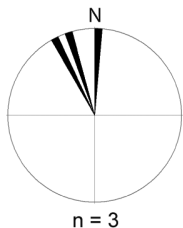

Fig. 2.- Sketch and rose plots from the selected sauropod tracksites from the Iberian Peninsula (Part I). 1) Galinha tracksite (modified from Santos et al., 1994; 2009). 2) Avelino tracksite (modified from Lockley and Santos, 1993). 3) Pedra da Mua level 3 tracksite (modified from Lockley et al., 1994a). Note that the trackways PM-N3-P10 and PM-N3-P11 are not figured. 4) Pedra da Mua level 5 tracksite (modified from Meyer et al., 1994). 5) Miraflores I tracksite (modified from Latorre Macarrón et al., 2006)

on the basis of the trackway gauge categories: narrow, intermediate and wide (see Wright, 2005; Marty, 2008) follows the original publications and was verified in the field.

\section{Description of selected sauropod tracksites and trackways}

\subsection{Galinha tracksite (Middle Jurassic)}

Galinha (Portugal) is the oldest sauropod tracksite in the Iberian Peninsula. At least 10 sauropod trackways have been described (Santos et al., 1994, 2009) within a surface of about $40,000 \mathrm{~m}^{2}$, several of these trackways measuring more than $100 \mathrm{~m}$ in length. The directions of movement of the sauropods are highly variable (Fig. 2.1, Supplementary online material), and the rose plot shows a multidirectional pattern. The only trackways that preserved the pes footprints (G1, G2 and G5) are large-sized (Supplementary online material).

\subsection{Avelino and Pedra da Mua tracksites (Late Jurassic)}

The Avelino tracksite (Lockley and Santos, 1993; Santos, 2003) and the Pedra da Mua tracksite (Lockley et al., 1994a; 
Santos, 2003, 2008) are the only sites from the Late Jurassic of Portugal with numerous sauropod trackways preserved. On level three (sensu Lockley and Santos, 1993) of the Avelino tracksite the trackways do not display any preferential direction and the pattern is multidirectional (Fig. 2.2, Supplementary online material). The sauropod trackways are small, medium and large-sized (Supplementary online material).

The Pedra da Mua tracksite (Portugal) is composed of seven track levels, of which levels three and five are the most important in terms of the number of sauropod trackways (Figs. 2.3and 2.4). On level three, 11 sauropod trackways have been described. Ten of these trackways have been interpreted as an age-segregated herd of small (7 parallel trackways, PM-N3P1- PM-N3-P7) and larger sauropods (3 parallel trackways, PM-N3-P8, PM-N3-P10 and PM-N3-P11), which passed afterwards (Lockley et al., 1994a; Santos, 2003, 2008). In the rose diagram this is expressed by the unidirectional orientation pattern of these trackways (Fig. 2.3). Nonetheless, the whole diagram represents a bimodal trackway orientation pattern due to the manus-only trackway PM-N3-P9, which shows a similar orientation but the opposite direction. The average pes length indicates a small to medium-sized class for these trackways. In layer five of the Pedra da Mua tracksite, five sauropod trackways with different directions of movement have also been described (Meyer et al., 1994; Santos, 2003), and the corresponding plot shows a multidirectional orientation pattern (Fig. 2.4). PM-N5-P3 and PMN5-P4 show roughly similar directions of movement and similar preservation, but since the other parameters (speed, intertrackway spacing) are slightly different (Supplementary online material), this has been interpreted as a poor evidence for gregariousness. Even thoughPM-N5-P1 and PM-N5-P5 have similar directions of movement; their preservation is completely different (PM-N5-P5 is a manus-only trackway). In this layer, the trackways fall within the medium to largesized class.

\subsection{Las Cerradicas tracksite (Late Jurassic - Early Cretaceous)}

In the Jurassic-Cretaceous transition there are many tracksites described from the Villar del Arzobispo Formation, but only at Las Cerradicas have clear sauropod trackways been preserved (Castanera et al., 2011). The six trackways are small-sized, parallel, and have regular intertrackway spacing. The similar pace rhythm is noteworthy (see Fig. 10 in Castanera et al., 2011). The rose diagram shows a unidirectional pattern (Fig. 3.1, and supplementary online material).

\subsection{Miraflores I and Las Cuestas I tracksites (Early Cretaceous)}

Two large sauropod tracksites have been reported from the Berriasian (Huérteles Formation) of the Eastern Cameros Basin: the Miraflores I tracksite (Latorre Macarrón et al., 2006) and Las Cuestas I tracksite (Pascual-Arribas et al., 2008; Pascual-Arribas and Hernández-Medrano, 2011).
The Miraflores I tracksite is composed of several track levels, of which level VIII-B is the most interesting (Fig. 2.5). Recognition of the sauropod trackways is a difficult task due to the high dinoturbation index and the thinness of the different layers comprising the level as a whole. At least five trackways have been recognized on this large surface (Latorre Macarrón et al., 2006), yet only three of these seem really to be located on the same level. These three trackways show a unidirectional pattern with the trackways pointing N-NW. The pes length indicates a small to medium sized category (Fig. 2.5; Supplementary online material).

Las Cuestas I tracksite is composed of three different levels (Fig. 3.2), which preserve 1, 15 and 5 sauropod trackways, respectively (Pascual-Arribas and Hernández-Medrano, 2011). The second level, with 15 trackways shows a unidirectional orientation pattern in the rose diagram (Fig. 3.2A). Of the 15 trackways, 12 show a similar direction of movement, i.e. W-SW. There is some uncertainty as to whether the movement involved the passage of a single group or several groups. The parameters are not so different, but the outcrop conditions - with a lot of debris, plants etc. - make it difficult to prove either interpretation. On level III the directions of movement vary, pointing towards the $\mathrm{W}, \mathrm{SW}$ and $\mathrm{SE}$, and the plot is multidirectional (Fig. 3.2B). The trackways from Las Cuestas I tracksite fall within the medium-sized category.

\subsection{Fumanya tracksites (Late Cretaceous)}

Fumanya tracksites yield the largest sample of sauropod trackways from the Iberian Peninsula; 51 sauropod trackways have been reported in four different tracksites from the same quarry, all belonging to a single track-bearing level, though some of these trackways have now been lost to erosion (Vila et al., 2008). The largest surface is Fumanya Sud, which has yielded 41 trackways, though not all are currently preserved. Only 21 trackways have thus been selected in this study, which are those where the data are most accurate. The roseplot of these trackways shows a multidirectional orientation pattern (Fig. 3.3), and only two groups of two trackways (FS \# 21- FS \#26 and FS \#27- FS \#28) exhibit parallel alignment close intertrackway spacing and similar speed values (Supplementary online material).

\section{Discussion}

\subsection{Orientation patterns of the Iberian sauropod trackways}

The study of dinosaur gregariousness on the basis of trackways intuitively demands track levels with considerable exposure areas to allow identification of multiple and parallel trackways. Tracksites with a very large surface and a low number of trackways would be good evidence of solitary behaviour. Although small surfaces can also record gregarious behaviour (e.g. Castanera et al., 2011), the absence of parallel trackways in some of the small tracksites does not 

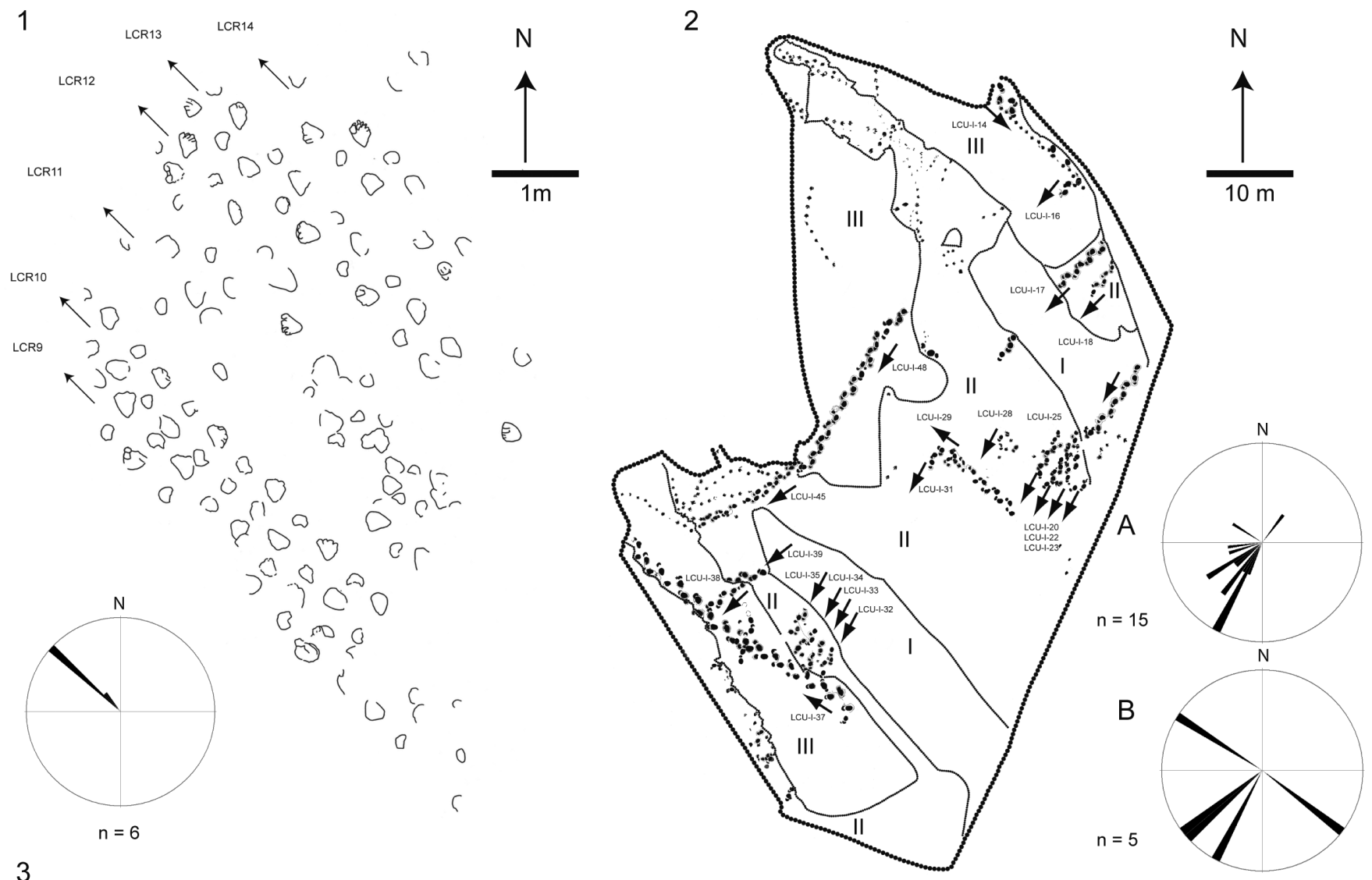

3

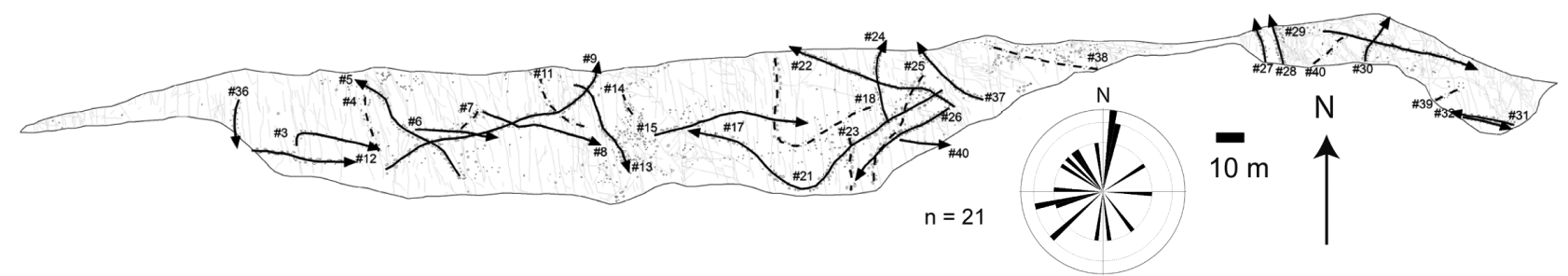

Fig. 3.- Sketch and rose plots from the selected sauropod tracksites from the Iberian Peninsula (Part II). 1) Las Cerradicas tracksite (modified from Castanera et al., 2011). 2) Las Cuestas I (level II and level III) tracksite (modified from Pascual-Arribas and Hernández-Medrano, 2011). 3) Fumanya Sud tracksite (modified from Vila et al., 2008).

prove its absence, since small surfaces produce a considerable bias, and if enlarged the evidence may rapidly change. Whatever the size of the surface, the orientation patterns of the trackways may reveal behavioural traits. Whereas unidirectional orientation patterns (combined with similar locomotion speed, regular intertrackway spacing, identical pace rhythm, etc.) are "the most convincing evidence" of gregarious behaviour (Ostrom, 1972; Thulborn, 1990; Lockley, 1997), random orientation patterns may indicate milling or any other irregular/untypical behaviour in a given area. These two different orientation patterns are referred to by Cohen et al. (1993) as directional and milling, respectively. As proposed by these authors, the former is a consequence of travel across the site, producing long, linear trackways, while the latter is represented by trackways that are "harder to decipher because they turn back and re-cross themselves many times". These authors also associate this kind of behaviour "with bedding sites, scent and scat marking stations, and feeding at patches of vegetation". The unidirectional orientation patterns could be a consequence of migration (on an unknown scale). A bimodal orientation pattern has often been associated with physical restrictions, i.e. natural barriers such as shorelines, river-banks, patches of dense vegetation (Lockley et al., 1986; Thulborn, 1990; Lockley, 1991), or even palaeogeographical constraints on a more regional scale (Moratalla and Hernán, 2010). A multidirectional or randomly distributed orientation pattern, on the other hand, may suggest individual movement.

Analysis of the rose diagrams of the studied localities yields two different patterns: a) a random, multidirectional distribution (Fig. 2.1, 2.2, 2.4, 3.2B, 3.3), and b) a preferential, unidirectional distribution (Fig. 2.3, 2.5, 3.1, 3.2A).

A unidirectional orientation pattern is reported from Pedra da Mua level 3, Las Cerradicas, Las Cuestas I level II 

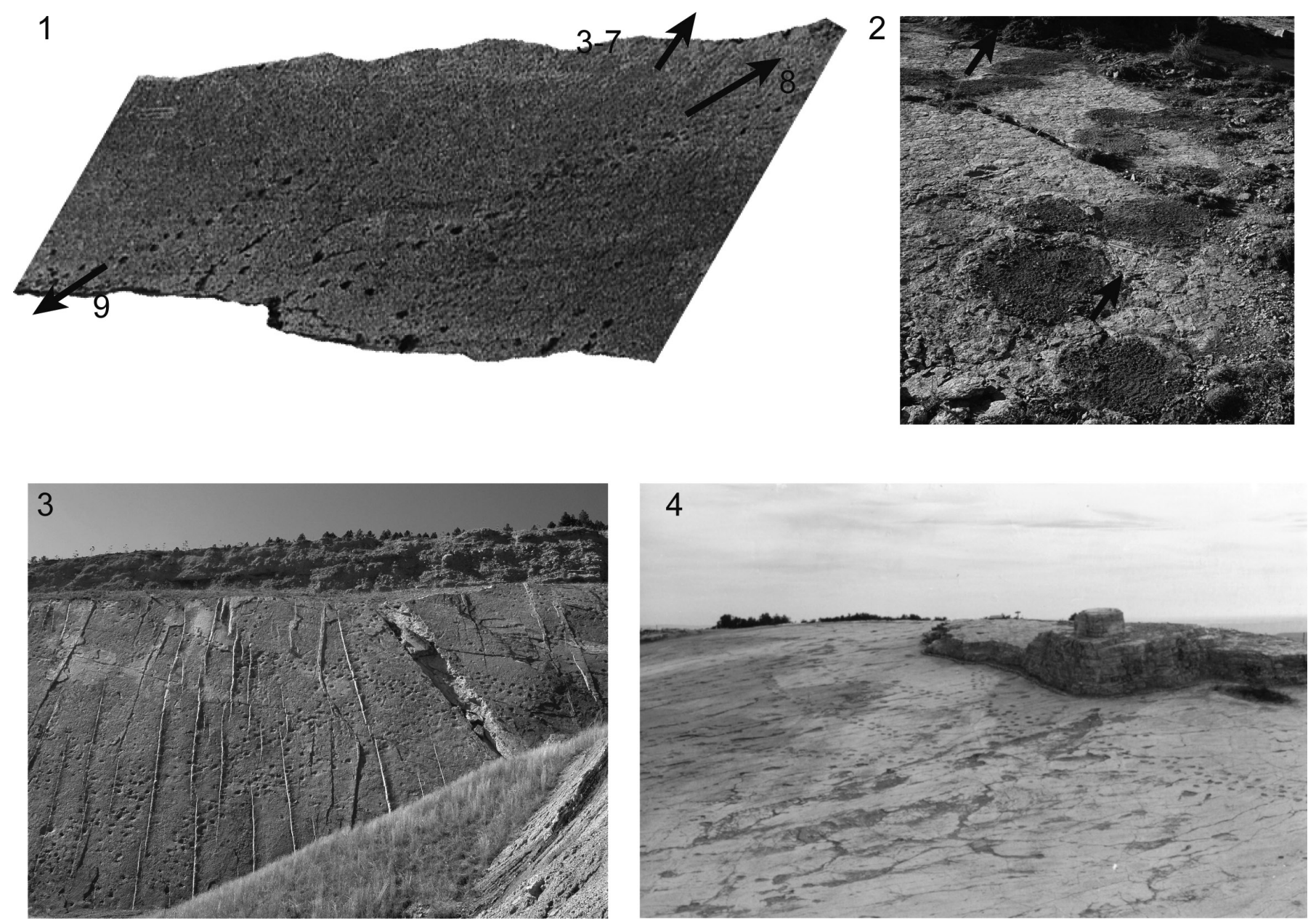

Fig. 4.- 1) Panoramic overview of Pedra da Mua level 3 tracksite (photograph by Pedro J.N. Silva). Note that the trackways PM-N3-P10 and PM-N3-P11 are out of the picture (see Fig.3 in Lockley et al., 1994a). 2) Photograph of the trackways LCU-I-34 (upper part of the picture) and LCU-I-35 (lower part of the picture) from Las Cuestas I tracksite. Note that the tracks are infilled with sand in order to highlight the trackway.

3) Partial panoramic overview from the Fumanya Sud tracksite. 4) Panoramic overview of the Galinha tracksite.

(Fig. 2.3, 3.1, 3.2A), some trackways from Miraflores I level VIII-B (Fig. 2.5), and Fumanya Sud (Fig. 3.3). In all these cases, this is interpreted as evidence for gregariousness, and this interpretation is supported by similar locomotion speeds, regular intertrackway spacing, and in some cases similar pace rhythms (Supplementary online material).

The unidirectional patterns reported in Pedra da Mua level 3, Las Cerradicas, Las Cuestas I (trackways on level II), and possibly Miraflores I (trackways MI-VIII-B-2, MI-VIII-B-3 and MI-VIII-B-4) reflect gregarious behaviour sensu stricto, where a group was moving simultaneously and with the animals aligned side by side (Fig. 4.1, 4.2; see Fig. 10 in Castanera et al., 2011). The purpose of such movement is unknown, and the length of the trackways is not in itself enough to justify any further-reaching hypothesis. Interestingly, the Fumanya Sud tracksite exhibits both milling (see Fig. 7 in Vila et al., 2008) and directional orientation patterns (Fig. 4.3), for it contains pairs of long, parallel trackways made by medium individuals, as well as many crossing trackways left by animals moving individually (Le Loeuff and Martínez, 1997; Schulp and Brokx, 1999; Vila et al., 2008). Thus, we concur with Lockley et al. (2002a) that the Fumanya Sud tracksite shows "a congregation of many individuals in the same area and occasional passage of several individuals in the same direction". The multidirectional orientation patterns of Galinha and Pedra da Mua level 5 both include long, straight trackways (directional) and turning trackways with considerable changes in direction (milling), (Figs. 2.1, 2.4; 4.4). The trackways from Avelino are straight (directional), and the trackway orientation pattern is random. However, the surface is not large enough (no turning trackways) to interpret this as milling. In Las Cuestas I level III most of the trackways are straight (directional), but at least one trackway also shows considerable changes in the direction of travel (Castanera et al., 2012) and could therefore be interpreted as milling.

Finally, the low percentage of tracksites with evidence of gregarious behaviour in the Iberian Peninsula (5 at the most, out of more than 100 sites) indicates that this kind of behaviour is rarely preserved in the fossil record even though many tracksites reflect the activity of sauropods in a particular palaeoenvironment. This concurs with the global record, where 


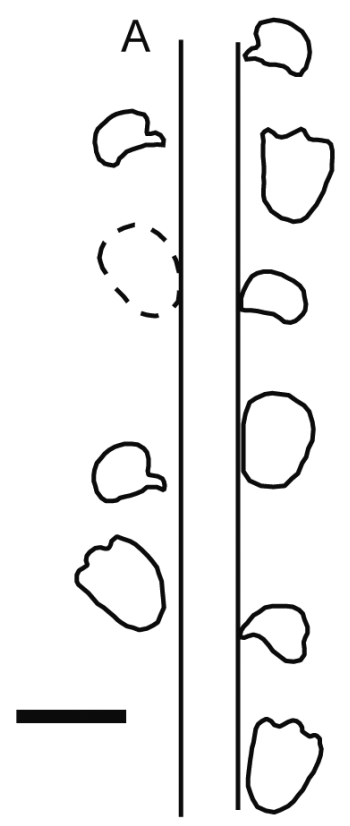

2

$\mathrm{B}$

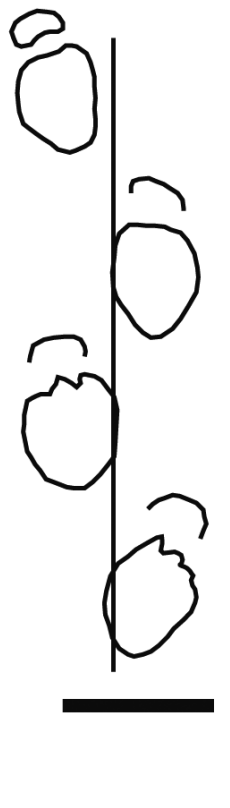

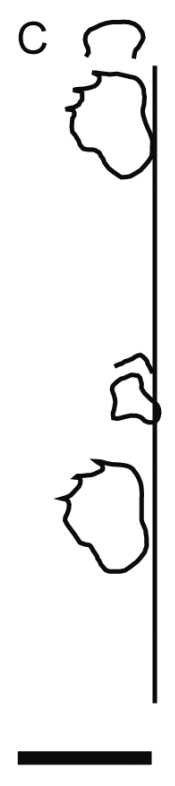

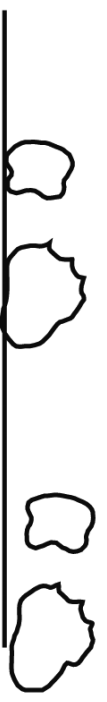

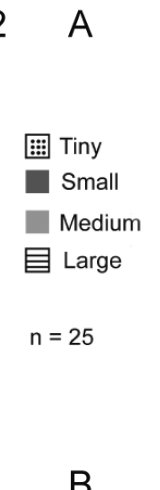

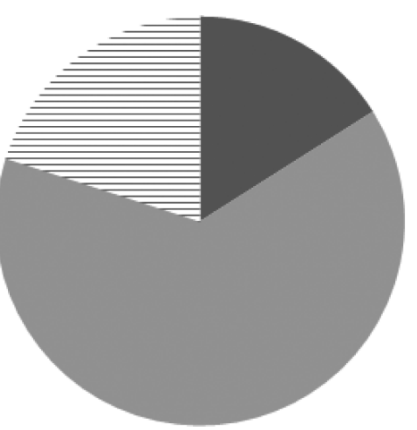

B

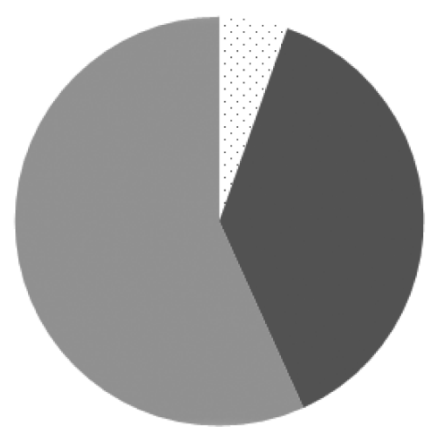

Fig. 5.- 1) Reference trackways of the main sauropod ichnotypes (Polyonyx-like, Parabrontopodus/Breviparopus-like, Brontopodus-like) described in the global record. 1A) Polyonyx gomesi (from Santos et al., 2009); 1B) Parabrontopodus mcintoshi (from Lockley et al., 1994b); 1C) Brontopodus birdi (from Lockley et al., 1994b). Scale bars $=1 \mathrm{~m}$. 2) Circular diagrams representing the size of the sauropod inferred from the studied trackways from the Iberian Peninsula. 2.A) non-gregarious sauropods. 2.B) gregarious sauropods. Note that the manus-only trackways and those with bad preservation have not been represented in the diagrams.

the number of sauropod tracksites with gregarious behaviour (Myers and Fiorillo, 2009) represents only a low percentage of the total sauropod tracksites (Wright, 2005; Mannion and Upchurch, 2010). However, it may be related to the bias produced by the palaeoenvironmental setting, the fact that most tracksites are too small in surface area, or the fact that sauropods were not gregarious for most of the time.

\subsection{Taxonomic, palaeoecological and palaeoenvironmental implications}

Sauropodomorph ichnotypes can be subdivided into five categories, which are associated with different trackmakers (Avanzini et al., 2003; Santos et al., 2009): these include Polyonyx-like, which are associated with non-neosauropod eusauropods (Santos et al., 2009); Parabrontopodus-like/ Breviparopus-like, associated with mainly diplodocid neosauropods; and Brontopodus-like, associated with titanosauriforms (Lockley et al., 1994b; Wilson and Carrano, 1999; Wright, 2005; Marty et al., 2010). Among the sauropod ichnotypes in the global track record (Fig. 5.1), gregarious behaviour has only been described in association with Parabrontopodus-like/Breviparopus-like and Brontopoduslike ichnotypes (Lockley et al., 1986; 1994b; 2002a; 2002b; Lockley and Meyer, 2000; Mezga et al., 2007; Marty, 2008) or among other sauropods not yet associated with a specific ichnotype (Leonardi, 1994; Day et al., 2004).
In the Iberian tracksites the evidence for gregarious behaviour is provided by narrow-gauge trackways (Las Cuestas I) and intermediate to wide-gauge trackways (Pedra da Mua level 3, Las Cerradicas, Miraflores I, Fumanya Sud), some of which could well conform to both Parabrontopoduslike/Breviparopus-like and Brontopodus-like ichnotypes. The sauropod trackways from Pedra da Mua level 3 and Fumanya Sud have been assigned to Brontopodus (Lockley et al., 1994a; Lockley and Meyer, 2000; Vila et al., 2008). The sauropods from Las Cerradicas and Miraflores I (the trackways MIVIII-B-2 to MI-VIII-B-4) have not been assigned to any ichnogenus, but could be classified as Brontopodus-like forms sensu lato despite the significant differences in the manus shape in the former (U-shaped $v s$. kidney-shaped) and the poor preservation of the latter. Likewise, the sauropod trackways from Las Cuestas I could be classified as Parabrontopoduslike/Breviparopus-like forms sensu lato (Pascual-Arribas and Hernández-Medrano, 2011). The other sauropod trackways, which do not show evidence of gregarious behaviour, such as Galinha, Avelino or Pedra da Mua level 5, have been assigned to Polyonyx (Santos et al., 2009), Parabrontopodus (Lockley and Santos, 1993; Santos, 2003) and Brontopodus (Meyer et al., 1994;Santos, 2003) respectively.

The Galinha tracksite is one of the oldest sauropod tracksites reported in the world, and despite the huge track level area (about $40,000 \mathrm{~m}^{2}$, Fig. 3.4) where these trackways are preserved gregarious behaviour has not been identified. 
Trackway G5 is the type trackway of the Polyonyx ichnogenus. Based on skeletal evidence, gregarious behaviour has been described in the Early and Middle Jurassic in some non-neosauropod eusauropods (see Myers and Fiorillo, 2009, and references therein), so this lack of evidence based on footprints seems not to be taxonomic. These authors have also suggested that sauropods "exhibited social behaviour throughout most, if not all of their history"

Our analysis also reveals that in all the sites where a multidirectional pattern is reported, most of the solitary trackmakers were of medium or large size and that there is very little evidence of solitary individuals of small size (Fig. 5.2A). At Galinha, the quadrupedal trackways (manus and pes tracks preserved) are large in size ( $\mathrm{PL}=80$ to $95 \mathrm{~cm})$. At Avelino there is a variation from small $(\mathrm{PL}=30 \mathrm{~cm})$, medium $(\mathrm{PL}=$ $45-55 \mathrm{~cm}$ ) to large-sized (PL $\sim 100 \mathrm{~cm}$ ). At Pedra da Mua (level 5) the sauropods are of medium size $(\mathrm{PL}=60-69 \mathrm{~cm}$ ) to large size $(\mathrm{PL}=80 \mathrm{~cm})$, and Fumanya Sud contains trackways of medium-sized individuals ( $\mathrm{PL} \sim 56-71 \mathrm{~cm}$ ). By contrast, gregarious behaviour inferred from unidirectional patterns is documented mainly in two of the size classes (small and medium), large individuals being not represented (Fig. 5.2B). The Iberian track record, as is the case in other areas of the global record (Myers and Fiorillo, 2009), indicates that groups of sauropods are generally composed of one size class. There are groups composed of tiny-small individuals (Las Cerradicas), small (Pedra da Mua level 3, PM-N3-P1 to PM-N3-P7) and of small to medium-sized individuals (Las Cuestas I, level 2). The gregarious sauropods of Miraflores I are small to medium $(\mathrm{PL}=29-55 \mathrm{~cm})$, while those of Pedra da Mua level 3 (PM-N3-P8, PM-N3-P10, PM-N3-P11) and Fumanya Sud are medium but some of them close to the large class (PL $\sim 56-73 \mathrm{~cm}$ ). Thus, it should be pointed out that in some of these tracksites, despite the fact that the trackways fall within the medium-sized category, the trackmakers can be considered as adults when compared with the smallest trackways (e.g. Pedra da Mua level 3 or Fumanya Sud). In the case of Las Cuestas I, the maximum pes length is $73 \mathrm{~cm}$, so the gregarious trackways ( $\mathrm{PL} \sim 50 \mathrm{~cm}$ ) could be adults or subadults but not juveniles. It is worth underscoring that small individuals almost always seem to travel in groups (except in the Avelino tracksite). Therefore, gregariousness in sauropods may be an age-related behaviour, as was suggested by Myers and Fiorillo (2009).

The first global assessments of the sauropod track record concluded that most of the trackways occurred in coastal and lacustrine environments in tropical and subtropical latitudes (Lockley et al., 1994c). Nonetheless, subsequent studies have pointed out the greater potential for track preservation in coastal than in inland environments (Wright, 2005). On the basis of skeletal and ichnological remains, Butler and Barrett (2008) found that the clade of sauropods shows a preference for inland environments; more recently, Mannion and Upchurch (2010) have associated non-titanosaurs (narrowgauge trackways) with coastal environments and titanosaurs (wide-gauge trackways) with inland environments. As for gregarious behaviour, this has been described in both coastal and inland environments in the global record (Wright, 2005; Myers and Fiorillo, 2009; Mannion and Upchurch, 2010) as well as in the Iberian tracksites. In the latter case, all the tracksites are preserved in coastal environments except those located in the Cameros Basin (Las Cuestas I, Miraflores I; Supplementary online material). In the Iberian Peninsula, gregarious behaviour in sauropods is mainly represented by intermediate to wide-gauge trackways with titanosauriform characters in coastal (Pedra da Mua, Las Cerradicas, Fumanya Sud) and inland (Miraflores I?) environments and by narrow-gauge trackways of non-titanosauriforms in inland environments (Las Cuestas I). This seems to contradict the taxonomic preference based on environment expressed by Mannion and Upchurch (2010).

\section{Conclusions}

In the sauropod tracksites of the Iberian Peninsula, evidence for gregarious behaviour in sauropods is scarce despite there being over 100 known sauropod tracksites. Nonetheless, two different trackway orientation patterns can be observed: directional orientation patterns and random orientation patterns. In some cases the directional pattern represents the movement of a group of sauropods, while in other cases it represents trackways of solitary individuals. The random orientation patterns are interpreted as milling or/and solitary behaviour. The sauropods that show gregarious behaviour in the tracksites of the Iberian Peninsula and the global record belong to the Parabrontopodus/Breviparopus-like and Brontopodus-like ichnotypes, associated with non-titanosauriform neosauropods (diplodocids) and titanosauriforms respectively. Up to now there is no evidence of gregarious behaviour associated with the Middle Jurassic Polyonyx-like ichnotype, associated with more basal sauropods (non-neosauropod eusauropods). The gregarious sauropods from the Iberian Peninsula are mainly small to medium-sized, which are the most abundant size classes even though this behaviour is also recorded in larger, adult individuals. All the Iberian tracksites with gregarious behaviour are preserved in coastal environments except those located in the Cameros Basin, which are probably preserved in more inland environments.

\section{Acknowledgements}

This paper forms part of the projects CGL2010-16447 and CGL2011-30069-C02-01, subsidized by the Ministry of Economics and Competition, the European Regional Development Fund and the Government of Aragón, Spain ("Grupos Consolidados" and "Dirección General de Patrimonio Cultural"). This study was also funded by the PEst-OE/CTE/ UI0611/2012 Project from the Centro de Geofísica da Universidade de Coimbra (Portugal). DC is the beneficiary of a grant from the Ministry of Education (AP2008-01340). 
This author also acknowledges the support of a grant from the Europa Cai-DGA program (CB 5/11). BV acknowledges support from the Ministry of Science and Innovation (Subprograma Juan de la Cierva (MICINN-JDC, 2011). The authors want to acknowledge Alvaro Jalles, Celia Caciones, Gabriel Mendes, Marta Borges, Paulo Rodrigues, Sara Brito and Vitor Amendoeira members of the Federação Portuguesa de Espeleologia, for their help during the field trip and access to the Pedra da Mua tracksites and to Pedro J. N. Silva (Departamento de Biologia Vegetal, Universidade de Lisboa, Portugal) for the graphic material on the aforementioned tracksites, and Laura Piñuela (Museo Jurásico de Asturias) for the information provided on the Asturian tracksites. The authors also acknowledge the comments of the referees, José Carlos García-Ramos, Daniel Marty and José Ignacio RuizOmeñaca, and the editors which have greatly improved the manuscript. Rupert Glasgow revised the English grammar.

\section{References}

Alexander, R.M. (1976): Estimates of speeds of dinosaurs. Nature 261, 129-130. doi:10.1038/261129a0

Avanzini, M., Leonardi, G., Mietto, P. (2003): Lavinipes cheminii ichnogen., ichnosp. nov., a possible sauropodomorph track from the Lower Jurassic of the Italian Alps. Ichnos 10, 173-193. doi: $10.1080 / 10420940390256195$

Azeredo, A.C. (2007): Formalização da litostratigrafia do Jurássico Inferior e Médio do Maciço Calcário Estremenho (Bacia Lusitânica). Comunicações Geológicas 94, 29-51.

Barco, J.L., Canudo, J.I., Ruiz-Omeñaca, J.I. (2006): New data on Therangospodus oncalensis from the Berriasian Fuentesalvo tracksite (Villar del Río, Soria, Spain): an example of gregarious behaviour in theropod dinosaurs. Ichnos 13, 237-248. doi:10.1080/10420940600843682

Butler, R.J. Barrett, P.M. (2008): Palaeoenvironmental controls on the distribution of Cretaceous herbivorous dinosaurs. Naturwissenschaften 95, 1027-1032. doi: 10.1007/s00114-008-0417-5

Castanera, D., Barco, J.L., Díaz-Martínez, I., Herrero-Gascón, J., PérezLorente, F., Canudo, J.I. (2011): New evidence of a herd of titanosauriform sauropods from the Lower Berriasian of the Iberian range (Spain). Palaeogeography, Palaeoclimatology, Palaeoecology 310, 227-237. doi: 10.1016/j.palaeo.2011.07.015

Castanera, D., Pascual, C., Canudo, J.I., Hernández, N., Barco, J.L. (2012): Ethological variations in gauge in sauropod trackways from the Berriasian of Spain. Lethaia, 45, 476-489. doi: 10.1111/j.15023931.2012.00304.x

Cobos, A. (2011): Los dinosaurios de Teruel como recurso para el desarrollo territorial. Unpublished $\mathrm{PhD}$ thesis. Universidad del País Vasco. $560 \mathrm{p}$.

Cohen, A.S., Halfpenny, J., Lockley, M., Ellinor, M. (1993): Modern vertebrate tracks from Lake Manyara, Tanzania and their paleobiological implications. Paleobiology 19(4), 433-458. doi: 00948373/93/1904-0004/\$1.00

Day, J.J., Norman, D.B., Gale, A.S., Upchurch, P., Powell, P. (2004): A Middle Jurassic dinosaur trackway site from Oxfordshire, UK. Palaeontology 47(2), 319-348.

García-Ortiz de Landaluce, E. Díaz-Martínez, I. (2008): Aportaciones de algunos yacimientos representativos de La Rioja al estudio del comportamiento de los dinosaurios. In: J. Esteve and G. Meléndez (eds.), Palaeontologica Nova. Publicaciones del Seminario de Paleontología de Zaragoza, volumen 8, Zaragoza: 207-219.

García-Ramos, J.C., Piñuela, L. Lires, J. (2006): Atlas del Jurásico de
Asturias. Ediciones Nobel, Oviedo, 1-225 p.

González-Riga, B.J. (2011): Speeds and stance of titanosaur sauropods: analysis of Titanopodus tracks from the Late Cretaceous of Mendoza, Argentina. Anais da Academia Brasileira de Ciências 83(1), 279-290.

Hernández Medrano, N., Pascual Arribas, C., Latorre Macarrón, P., Sanz Pérez, E. (2008): Contribución de los yacimientos de icnitas sorianos al registro general de Cameros. Zubía 23-24, 79-120.

Latorre Macarrón, P., Pascual Arribas, C., Sanz Pérez, E., Hernández Medrano, N. (2006): El yacimiento con huellas de saurópodos de Miraflores I, Fuentes de Magaña (Soria, España). In: Colectivo Arqueológico-Paleontológico Salense (eds.). Actas de las III Jornadas Internacionales sobre Paleontología de Dinosaurios y su Entorno. Salas de los Infantes, Burgos: 273-296.

Le Loeuff, J., Martínez, A. (1997): Afloramiento de icnitas de Titanosauridae en la zona de Fumanya (Maastrichtiense, Pirineo oriental): estudio preliminar. Geogaceta 21, 151-153.

Leonardi, G. (1994): Annotated Atlas of South America tetrapod footprints (Devonian to Holocene). Publication of the Companhia de Pesquisa de Recursos Minerais: 248 p.

Lockley, M.G. (1991): Tracking Dinosaurs: A new Look at an Ancient World. Cambridge University Press, Cambridge: 238 p.

Lockley, M.G. (1997): The paleoecological and paleoenvironmental utility of dinosaur tracks. In: J.O. Farlow and M.K. Brett-Surman (eds.), The Complete Dinosaur. Indiana University Press: 554-578.

Lockley, M.G., Santos, V.F. (1993): A preliminary report on sauropod trackways from the Avelino site, Sesimbra region, Upper Jurassic Portugal. Gaia 6, 38-42.

Lockley, M.G, Meyer, C. (2000): Dinosaur tracks and other fossil footprint of Europe. Columbia University Press. New York: 323 p.

Lockley, M.G., Houck, K.J., Prince, N.K. (1986): North America's largest dinosaur trackway site: Implications for Morrison Formation paleoecology. Bulletin of the Geological Society of America 97, 1163-1176.

Lockley, M.G., Meyer, C.A., Santos, V.F. (1994a): Trackway evidence for a herd of juvenile sauropods from the Late Jurassic of Portugal. In: M.G. Lockley, V. F. dos Santos, C. A. Meyer, A. Hunt (eds.), Aspects of Sauropod Paleobiology.Gaia 10, 27-35.

Lockley, M.G., Farlow, J.O., Meyer, C.A. (1994b): Brontopodus and Parabrontopodus ichnogen. nov. and the significance of wide- and narrow-gauge sauropod trackways. In: M.G. Lockley, V. F. dos Santos, C. A. Meyer, A. Hunt (eds.), Aspects of Sauropod Paleobiology. Gaia 10, 135-145.

Lockley, M.G., Meyer, C.A., Hunt, A.P., Lucas, S.G., (1994c): The distribution of sauropod tracks and trackmakers. In: M.G. Lockley, V. F. dos Santos, C. A. Meyer, A. Hunt (eds.), Aspects of Sauropod Paleobiology. Gaia, 10, 233-248.

Lockley, M.G, Schulp, A.S., Meyer, C.A., Leonardi, G. Mamani, D.K. (2002a): Titanosaurid trackways from the Upper Cretaceous of Bolivia: evidence for large manus, wide-gauge locomotion and gregarious behaviour. Cretaceous Research 23, 383-400. doi: 10.1006/ cres.2002.1006

Lockley, M.G, Wright, J., White, D., Matsukawa, M., Li, J., Lu, F. Hong, I. (2002b): The first sauropod trackways from China. Cretaceous Research 23, 363-381. doi: 10.1006/cres.2002.1005

Lockley, M., García-Ramos, J. C., Piñuela, L., Avanzini, M. (2008): A review of vertebrate track assemblages from the Late Jurassic of Asturias, Spain with comparative notes on coeval ichnofaunas from the western USA: implications for faunal diversity in siliciclastic facies assemblages. Oryctos 8, 53-70.

Mannion, P.D., Upchurch, P. (2010): A quantitative analysis of environmental associations in sauropod dinosaurs. Paleobiology 36(2), 253-282. doi: 0094-8373/10/3602-0005

Marty, D. 2008: Sedimentology, taphonomy, and ichnology of 
Late Jurassic dinosaur tracks from the Jura carbonate platform (Chevenez-Combe Ronde tracksite, NW Switzerland): insights into the tidal-flat palaeoenvironment and dinosaur diversity, locomotion, and palaeoecology. GeoFocus 21, Fribourg University (Switzerland): $278 \mathrm{p}$.

Marty, D., Belvedere, M., Meyer, C. A., Mietto, P., Paratte, G., Lovis, C., Thüring, B. (2010): Comparative analysis of Late Jurassic sauropod trackways from the Jura Mountains (NW Switzerland) and the central High Atlas Mountains (Morocco): implications for sauropod ichnotaxonomy. Historical Biology 22(1-3), 109-133.

Meyer, C.A., Lockley, M.G., Robinson, J., Santos, V.F. (1994): A comparison of well-preserved sauropod tracks from the Late Jurassic of Portugal and the Western United States: evidence and implications. In: M.G. Lockley, V. F. dos Santos, C. A. Meyer, A. Hunt (eds.), Aspects of Sauropod Paleobiology. Gaia 10, 57-64.

Mezga, A., Cvetko Tesovic, B., Bajraktarevic, Z. (2007): First record of dinosaurs in the Late Jurassic of the Adriatic-Dianridic carbonate platform (Croatia). Palaios 22, 188-189. doi: 10.2110/palo.2006.p06$043 r$.

Moratalla, J.J. (2009): Sauropod tracks of the Cameros Basin (Spain): identification, trackway patterns and changes over the Jurassic-Cretaceous. Geobios 42, 797-811. doi:10.1016/j.geobios.2009.06.006.

Moratalla, J.J., Hernán, J. (2010): Probable palaeogeographic influences of the Lower Cretaceous Iberian rifting phase in the Eastern Cameros Basin (Spain) on dinosaur trackway orientations. Palaeogeography, Palaeoclimatology, Palaeoecology 295, 116-130. doi:10.1016/j.palaeo.2010.05.027.

Myers, T.S., Fiorillo, A.R., (2009): Evidence for gregarious behaviour and age segregation in sauropods. Palaeogeography, Palaeoclimatology, Palaeoecology 274, 96-104. doi:10.1016/j.palaeo.2009.01.002

Oms, O., Dinarès-Turell, J., Vicens, E., Estrada, R., Vila, B., Galobart, À., Bravo, A.M., (2007): Integrated stratigraphy from the Vallcebre Basin (southeastern Pyrenees, Spain): new insights on the continental Cretaceous-Tertiary transition in southwest Europe. Palaeogeography, Palaeoclimatology, Palaeoecology 255, 35-47

Ostrom, J.H.(1972): Were some dinosaurs gregarious? Palaeogeography, Palaeoclimatology, Palaeoecology 11, 287-301.

Pascual-Arribas, C., Hernández-Medrano, N. (2011): Nuevos datos sobre el yacimiento icnítico de Las Cuestas I (Santa Cruz de Yanguas, Soria. España). Studia Geologica Salmanticensia 46, 121-157.

Pascual Arribas, C., Hernández-Medrano, N., Latorre Macarrón, P. Sanz Pérez, E. (2008): Estudio de un rastro de huellas de saurópodo del yacimiento de Las Cuestas I (San Cruz de Yanguas, Soria, España). Implicaciones taxonómicas. Studia Geologica Salmanticensia 44, 13-40.

Pérez-Lorente, F. (2003): Icnitas de dinosaurios del Cretácico en España. In: F. Pérez-Lorente (coord.), Dinosaurios y otros reptiles mesozoicos de España. Fundación Patrimonio Paleontológico de La Rioja. Instituto de Estudios Riojanos (IER Ciencias de la Tierra, 26), 49-108.
Pérez-Lorente, F., Cuenca-Bescós, G., Aurell, M., Canudo, J.I., Soria, A.R., Ruiz-Omeñaca, J.I. (1997): Las Cerradicas tracksite (Berriasian, Galve, Spain): Growing evidence for quadrupedal ornithopods. Ichnos 5, 109-120. doi: 10.1080/10420949709386410.

Quijada, I.E., Suárez-González, P., Benito, M.I., Mas J.R., Alonso, A. (2010): Un ejemplo de llanura fluvio-deltaica influenciada por las mareas: el yacimiento de icnitas de Serrantes (Grupo Oncala, Berriasiense, Cuenca de Cameros, N. de España). Geogaceta 49, 15-18.

Royo-Torres, R. (2009): Los dinosaurios saurópodos en la Península Ibérica. In: P. Huerta, F. Torcida (eds.), Actas de las IV Jornadas Internacionales sobre Paleontología de Dinosaurios y su Entorno. Salas de los Infantes, Burgos: 139-166.

Santos, V.F. (2003): Pistas de dinossáurio no Jurássico-Cretácico de Portugal. Considerações paleobiológicas e paleoecológicas. Unpublished PhD. thesis, Universidad Autónoma de Madrid, Madrid: 365 p.

Santos, V.F. (2008): Pegadas de dinossáurios de Portugal. Museu Nacional de História Natural da Universidade de Lisboa, Lisboa, 123 pp. ISNB: 978-972-96491-7-2.

Santos, V.F., Lockley, M.G., Meyer, C.A., Carvalho, J., Galopim de Carvalho, A.M., Moratalla, J.J. (1994): A new sauropod tracksite from the Middle Jurassic of Portugal. In: M.G. Lockley, V. F. dos Santos, C. A. Meyer, A. Hunt (eds.), Aspects of Sauropod Paleobiology. Gaia 10: 5-13.

Santos, V.F., Moratalla, J.F., Royo-Torres, R. (2009): New sauropod trackways from the Middle Jurassic of Portugal. Acta Palaeontologica Polonica 54(3), 409-422. doi: 10.4202/app.2008.0049.

Schulp, A.S., Brokx, W.A. (1999): Maastrichtian sauropod footprints from the Fumanya site, Berguedà, Spain. Ichnos 6(4), 239-250. doi: 10.1080/10420949909386455.

Thulborn, T. (1990): Dinosaur tracks. Chapman and Hall, London: 410 p.

Vila, B., Oms, O., Galobart, À. (2005): Manus-only titanosaurid trackway from Fumanya (Maastrichtian, Pyrenees): further evidence for an underprint origin. Lethaia 38, 211-218. doi: $10.1080 / 00241160510013312$

Vila, B., Oms, O., Marmi, J., Galobart, A. (2008): Tracking Fumanya footprints (Maastrichtian, Pyrenees): historical and ichnological overview. Oryctos 8, 115-130.

Villalba-Breva, S., Martín-Closas, C., Marmi, J., Gomez, B., Fernández-Marrón, M.T. (2012): Peat-forming plants in the Maastrichtian coals of the Eastern Pyrenees. Geologica Acta 10(2) ,189-207. doi: $10.1344 / 105000001711$

Wilson, J.A., Carrano, M.T. (1999): Titanosaurs and the origin of "widegauge" trackways: a biomechanical and systematic perspectives on sauropod locomotion. Paleobiology 25(2), 252-267. doi: 00948373/99/2502-0009/\$1.00.

Wright, J.L. (2005): Steps in understanding sauropod biology: the importance of sauropod tracks. In: K.A., Curry Rogers, J.A. Wilson, (eds.), The Sauropods: Evolution and Paleobiology. University of California Press, 252-284 p.

Supplementary material: available online at $w w w$. revistas.ucm.es/index.php/JIGE

Main characteristics of the sauropod trackways from the studied Iberian sauropod tracksites (tables). 